\title{
Transforming the IT organization for $E$ - Business: A Perspective of Integration
}

\author{
Huang Jie and Guo Shuojia ${ }^{2}$ \\ 1 School of Business Administration, \\ ZhongNan University of Economics and Law, \\ Wuluo Road 114, 430060 Hubei Wuhan, P.R.China, \\ Rockychina66@163.com, \\ 2 School of Management \\ Huazhong University of Science and Technolofy
}

\begin{abstract}
In the context of E-business, IT organization designs meet the serious challenges. To allow the business to engage in IT-enabled E-business strategy initiatives, transforming traditional IT organization is imperative. As an effective method of solving complex problems and building organism, the theory of integration provides an original idea and methodology for the innovational transformation of IT organization. Based on the investigation of integration theory along with the relevant research results in the field of IRM, this paper explores and expounds the MCAS mode of IT organizational integration and explores the frameworks of IT organizational integration from three aspects of organizational member's competence, activity and structure and the transforming model of IT organization.
\end{abstract}

\section{Introduction}

Although there are endless mutation and variations of IT organization structures, these changes originate from traditional organizational design thinking and it was designed not to change but to preserve [1]. IT organizations are still viewed as machine bureaucracy and it becomes slow, inflexibility, creativeless and an Ebusiness obstacle to be overcome. In the context of E-Business, IT organizations need to be organic with flexibility and spontaneity. In order to efficiently exploit and utilize IT potential and advantage to support E-business strategy, the basic designing idea and model of IT organization should be changed.

As an effective method of solving complex problems and building organic whole, the theory of integration provides an original idea and methodology for the innovational transformation of IT organization. So the objective of this paper is to explore the basic ideas and application of integration in IT organization design and

Please use the following format when citing this chapter:

Jic, H., Shuojia, G., 2006, in International Federation for Information Processing, Volume 205, Research and Practical Issues of Enterprise Information Systems, eds. Tjoa, A.M., Xu, L., Chaudhry, S., (Boston:Springer), pp.173-179. 
offer a new integration-oriented theoretical approach to deal with the challenges of E-Business faced by IT organization.

This paper is divided in the following sections: firstly the investigations of related work are described along with the relevant research results on IT organizational integration. Secondly, based on analyzing the challenges of EBusiness on IT organizational design, the innovational integration-oriented idea of transformation of IT organization is expounded. Thirdly, the conceptual model of integration for the new transforming approach of IT organization is explored. Finally, the conclusion and the future research are summarized.

\section{Related work}

It is very clear in the history of IRM development that integration has become one of the core ideas in the fields of theory research and practice on IRM [2]. According the view of Horton [3], IT organization is an ensemble of several vocations in different IT fields and they should be integrated though they were isolated and scattered ago. Marchand and Kresslein [4] thought that the integrated management of the functions of "isolated islands" in IT organization is the necessary condition and important guarantee for extremely utilizing the advantages of IT in business. Hence, it became an effective way to transforming IT organization that integrating IT organization based on the functions of IT to solving the problem of "isolated islands".

CIO architecture represents the future transformational direction of IT organization. Rotes and Bonn [5] believed that the key of CIO architecture is the integration of some responsibilities which are originally taken by the separated fields or institutions. Pei [6] thought that the responsibility of IT organization shouldn't be limited by the functions of IT and should integrate some responsibilities of business and management Huo [6] proposed that the functions of IT organization should be integrated into four institutions including Strategy Planning center, Information Center, IT Center and E-Business Center.

Bernard [7] believed that traditional IT organization designing based on the views of job division and specialization and scattered activities and proposed that process is an important basis for transforming IT organizational structure. Furthermore, Brown and Ross, Sambamurthy [8] and Windley [9] described core IT activities from the view of managing IT functions and explored the integration modes of processes respectively.

The results of researches discussed above show that there are some flaws in those ideas and models of IT organization integration. Firstly, although those transforming design all applied the idea and method of integration in some degrees, the traditional designing thinking based on the division of work or function still in charge of the IT organizational integration. Secondly, those integration models didn't provide enough concern on the basic element of organization i.e. human. Although IT function integration, responsibility integration and process integration are related with human more or less, they didn't grasp the pivot point-the knowledge or skills possessed by members of IT organization. Thirdly, although those methods of IT organization integration reorganized the organization's institutions or members 
according to their functions and integrated them into the corresponding frame, they ignore the transformation of the ways of managing and controlling the members and their activities. The commanding mechanism of control and coordination is not only an obstacle for the cooperation, but also not beneficial for the promotion of organization's reactive capacity and the flexible level.

\section{Challenges and Innovation of IT organization}

\section{Objectives of IT organizational transformation}

To allow the business to engage in IT-enabled E-business strategy initiatives, IT organization design for E-business age meet the challenges and should archive following objectives:

1. Flexibility. A high degree of uncertainty remains in the ways of E-Business. So the IT organization should adapt to the changes of business circumstances and business requirements and provide IT support and service agilely.

2. Responsiveness. Time is a key factor of the competition in E-Business. In order to support E-Business strategy, IT organization should react promptly to changing business environments and enable business to execute all actions swiftly.

3. Collaboration. The essence of E-Business is the virtually collaborative value creation and so the members of IT organization should collaborate and work harmoniously together toward shared business aims.

4. Innovation. E-business is the transformation of business and innovation is the source of core competitiveness and competitive advantage in E-business era. So IT organization design should promote the exchange and share of knowledge and archive innovation in solving the problems of requirements in business transformation.

5. Spontaneity. Internet changes everything. IT organization is not just a bureaucratic machine but an organism. So the design of IT organization should permit it to evolve dynamically to stay in harmony with the changing circumstances and business.

Integration based on MCAS: Innovation of IT organization

As an effective method of solving complex problems and building organic whole, integration is identified by the behavior characteristics: positive and intentional, creative, dynamic, open and optimizing the whole Apparently, applying integration idea in the design of IT organization can utilize the advantages of integration and promote the achievement of the objectives of IT organization transformation.

With the specific functions and goals, IT organization is a system in which two or more persons work together according to a certain structure. IT organizational integration is the application of integration in the IT organizational design. As basic element of IT organization, human is the core of integration. According a certain mode, IT organizational integration makes every member into an organism and 
achieves radically promotion of the whole functions of IT organization through the mutual impacts between the members in the organization to provide better support and service for the strategy and business.

As a system, the achievement of the whole function of IT organization is the result of activities of members who work together in a certain structure. So in order to transformation IT organization, integration in enterprise IT organization should includes three important contents, integration of members' competences, integration of members' activities and integration of members' structure. Figure 1 summarizes the basic mode of integration in IT organizational design which named MCAS mode.

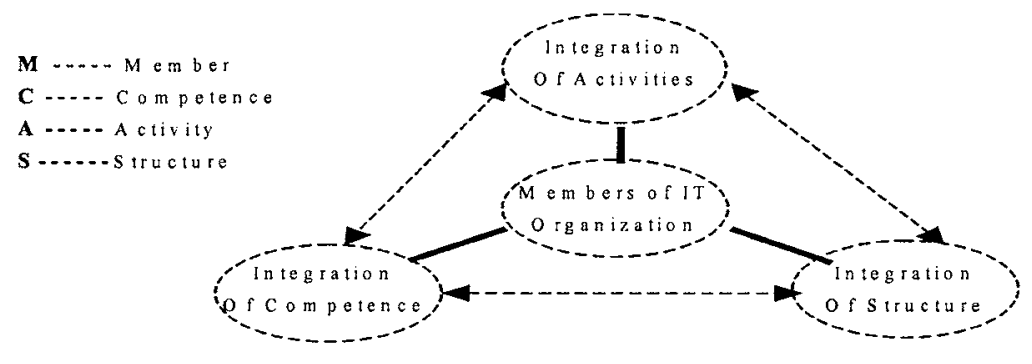

Figure $1: M$ CA S M ode of IT organizationalintegration

The MCAS integration mode of IT organization around the core of people is conformity with the human-centered managerial thinking and the integration in above three aspects also conform to the principle of alignment between the inside and outside of organizational strategy. Obviously, MCAS mode presents the advantages of integration on transforming IT organization.

1. Integration of competence attains the supplementary, competitive and harmonious relations among organizational member's competence and promotes the building of the core competence system of IT organization. Through sharing and exchanging knowledge and skill with others, IT organization can effectively exploit and utilize the potential of IT asset and information resources to support E-business strategy and meet E-business requirements creatively.

Generally, the capacity of IT organization is a group of skills which belong to each member separately and also involve in many aspects of the organization. However, just these separated skills couldn't produce great achievement. So, integrating the skills of members into an effective capacity system according to a certain reasonable framework is imperative. Sambamurthy [8], Feeny and Willcocks [10], Marchand, Kettinger and Rollins [11] eluciated that the capacity system of IT organization involves some different fields and several core abilities are the keys to establish an effective capacity system.

Based on these studies, we distinguish and define the core abilities of IT organization from four important aspects. These four core abilities comprise the capacity system of IT organization and provide the basic framework for the integration of members' competence. The ability of S\&D is oriented for the aspects of business and strategy. The ability of R\&D is oriented for the aspects of IT. The ability of A\&S is oriented for the aspects of business requirement support and 
service. The ability of RM is oriented for the aspects of the information resource and information activities.

2. Integration of activities breaks the restrictions of the specialized divisions of labor and reduces the cost of coordination and promotes collaboration in organization. Through integrating the traditional fragmentary work of organizational member into corresponding process, IT organization can not only improve individual working efficiency but also promote the whole efficiency of organization. With these reasonable and flexible business processes, IT organization can support E-business effectively swiftly.

According to Value Chain Theory, the value created by business actually comes from a series of activities. Process is a series of elaborately designed activities carried on for providing product or service for specific customers or market [12] and a customer-centered organization should increasingly be a process-oriented organization [13].

The definitions of IT organizational processes are not consolidated and mostly just focus on information technology [8, 9, and 14]. Obviously, it is partial to limit the definition of the processes of IT organization just into the scope of IT. According to Davenport's definition and description [12] about process, the definition of IT organization processes should face customers, moreover they should be aligned with organizational capabilities. Therefore, combining with IT organizational capabilities discussed above, the basic processes of IT organization can be generally divided into five aspects involving the strategic planning, the resource management, the exploitation and implementation of solution, the application support and service and customer management, which constitute the framework of integration of activities .

3. Integration of structure effectively makes various inside and outside relations and factors of organization structure (such as, relationships for report, the ways to control or make a decision and so on) become harmonious. Through integration of different organizational mechanisms, members of IT organization can conveniently and effectively communicate and coordinate with others, which should increasingly reduce the rigid degree of organization structure and erase the strict organizational boundary. This will not only enhance greatly the agility and adaptability of the IT organization but also promote the collaboration and innovation.

The traditional structure design partially emphasizes the stability, formalization and professional efficiency and ignores flexibility and spontaneity, hampers cooperation, creation and change. This kind of organizational structure becomes the barrier of organizational business changing ,Generally, the organizational structure stipulates in the work that the organization must do in the specific framework which involving some factors such as the reporting relations, the working procedure, the controlling structure, the authorization and the decision process etc. of the organization [15].

Hence, in order to transform IT organization and make it organically, Integration of structure should combine different organizational structure factors organically in a certain mode to form the competitive supplementary and harmonious relations among those organizational relationships. Based on the basic element of IT organization---human, we could distinguish the complicated relationships from four aspects including controlling method, connecting mechanism, working mode and decision mode which constitute the basic framework of integration of structure. 


\section{Conclusions}

Facing the challenges of E-Business, integration should become an important direction and method for transforming IT organization. MCAS transcends traditional design of IT organization based on utilizing integration theory extensively. According to the MCAS mode of IT organizational integration, we might transform traditional IT organization to be harmonious, flexible and creative and make IT organization effectively adapt to E-business circumstances and support the achievement of E-business strategy. Future researches will explore the measurement and evaluation of IT organizational integration and study the managerial mechanisms and tactics of IT organizational integration.

\section{References}

1. Bernard H. Boar, Redesigning the IT organization for the information age: Information Systems Management, 1998 15(3), Summer, p.23-30

2. Wang Weijun, Huang Jie, Li Biqiang, Study and Applying Exploration on Information Management Integration, Information Journal, 2003, 10, 526-531

3. Horton, Information Resource Management. Englewood, New Jersey: Prentice-Hall, Inc. 1985

4. Marchand Donald A, Kresslein John C. Information Resources management and Public Administration. See: Rabin, Jack and Jackowski, Edward M. Handbook of Information Resource Management, New York: Marcel Dekker, Inc., 1988ロp390-450

5. Rotes Y, Boon J A, Information Manager-An Exploration Study, South Journal of Library and Information Science, 1992(3), 137-145

6. Huo Guoqing, Yang Ying, Study on Information Structure Reconstruction of Chinese Large and Middle Scale Enterprise, Management Science Journal, 2001 (4), 33-36

7. Bernard H. Boar, Constructing blueprints for enterprise IT architectures, John Wiley \& Sons, Inc., New York, NY, 1998

8. Sambamurthy, The Governance and Structure of The IT Organization. ISRC Notes January 2000

9. Phillip J. Windley Modular IT Organization in Utah State Government. 2002, www.das.state.ut.us/cc/Mar2002

10. Feeny and Willcocks,. Core IS capabilities for exploiting information technology, Sloan Management Review Spring, 1998, p.9-21.

11. Marchand D., William J. Kettinger, Information Orientation: People, Technology, and the Bottom Line, Sloan Management Review, 2000.

12. Dvenport and $\mathbf{J}$ Short, The New Industrial Engineering, Information Technology and Business Process Redesign. Sloan Management Review, summer 1990, p32-41

13. Ghoshal and Bartlett, The Individualized Corporation. New York NY: Hoper Collins, 1997 14. Carol Ross et al, The IT Organization of the $21^{\text {st }}$ Century: Moving to a Process-Based Orientation, CISR working paper N306, 1999, 7.

15. Hitt M A et al, Strategic Management: Competitiveness and Globalization. (Mason, $\mathrm{OH}$ South-Western College Publishing, 2003).

16. Ravichandran et al, Stragetic Implications of Information Systems Resources and Capabilities: A Competence-Based Model, Proceedings of America Conference on Information Systems, 2000. 
17. Sinan A and Peter W, IT Assets, Organizational Capabilities and Firm Performance: Asset and Capability Specific Complementarities, CISR working paper 2004 No. 343.

18. Ikujiro Nonaka etc., The Knowledge-Creating Company (New York Oxford University Press, Inc. 1995.) 